\title{
Experimental evaluation of the influence of tool wear on the temperature in the cutting zone during the turning of metals
}

\author{
Viktor P. Lapshin ${ }^{1, *}$,Tatiana S. Babenko ${ }^{1}$, Valentin S. Minakov ${ }^{1}$, and Sergey I. Kambulov ${ }^{2}$ \\ ${ }^{1}$ Don State Technical University, 344000 Rostov-on-Don Gagarin square 1, Russia \\ ${ }^{2}$ State Scientific Establishment "Agriculture research center "Donskoy", North Caucasus Institute of \\ Mechanization and Electrification of Agriculture, 347740 Zernograd, Russia
}

\begin{abstract}
The work is devoted to the questions of experimental estimation of the influence of the degree of the tool wear, during turning of metals in metal-cutting machines, on the level of thermal energy in the contact area of the tool with the workpiece. In the work, the experimental method revealed that with the increasing of the tool wear along the back face, the power of the released thermal energy in the contact zone of the tool and the machined part increases. This is associated with an increase in the power of irreversible pre-formations in the contact area of the tool with the workpiece, the result of which is the growth of energy consumption and the growth of conversion of this energy into thermal energy in the contact zone. The main conclusion on the work can be a conclusion about the repetition of the appearance of the dependence of the level of thermal energy in the cutting zone on time, the graph of the dependence of the degree of deterioration of the instrument on time. Proceeding from this, we can talk about the possibility of linear interpolation of the heat level from the degree of wear during the synthesis of mathematical models of the processes accompanying the cutting of metals in metal cutting machines. From the point of view of a possible explanation of this connection, it can be that with the increase of the tool wear, the capacity of irreversible transformations in the workpiece and in the tool itself grows, and the result of the growth of this capacity is the increase in the power of the heat released during processing.
\end{abstract}

\section{Statement of the research task}

In the modern view of the problems of metalworking associated with tool wear, it is customary to distinguish two forms of wear development, wear of the front surface and dimensional wear or wear along the back edge of the cutting tool [1-4]. From the point of view of the effect of tool wear on the power of irreversible transformations, the greatest interest is the wear on the back edge, as a result of an increase in wear on the back face, the contact area of the tool grows and, as a consequence, the capacity of irreversible

\footnotetext{
* Corresponding author: lapshin1917@yandex.ru
} 
transformations in the contact zone increases. As a result of the development of wear along the back edge and the growth of the power of irreversible transformations, the temperature in the contact zone increases. Features of the complex dynamics of the control system for metal processing on metal-cutting machines, considered in [6-9], show that it is the dynamic features of the system that affect the power of irreversible transformations. At the same time, the issues related to the quality and efficiency of metal cutting in metal cutting machines are not sufficiently disclosed from the point of view of the formation of internal dynamic links in the process [10].

In the cutting system, some internal dynamic connection is formed through the coupling of the mechanical and thermodynamic system, which shows how the cutting control system is stabilized by increasing the energy dissipation in the cutting zone. In connection with this, a self-sufficient task arises that has a high scientific significance, determination of the parameters of the mechanical and thermodynamic subsystems connectedness in a single system that arises in the contact zone of the tool and the machined part during cutting.

\section{Description of the equipment and experiment used}

For the experiment, a lathe 1K625 (see Figure 1) was used, on which a stand was installed for studying the cutting conditions for turning the STD.201-1. shown in Fig.

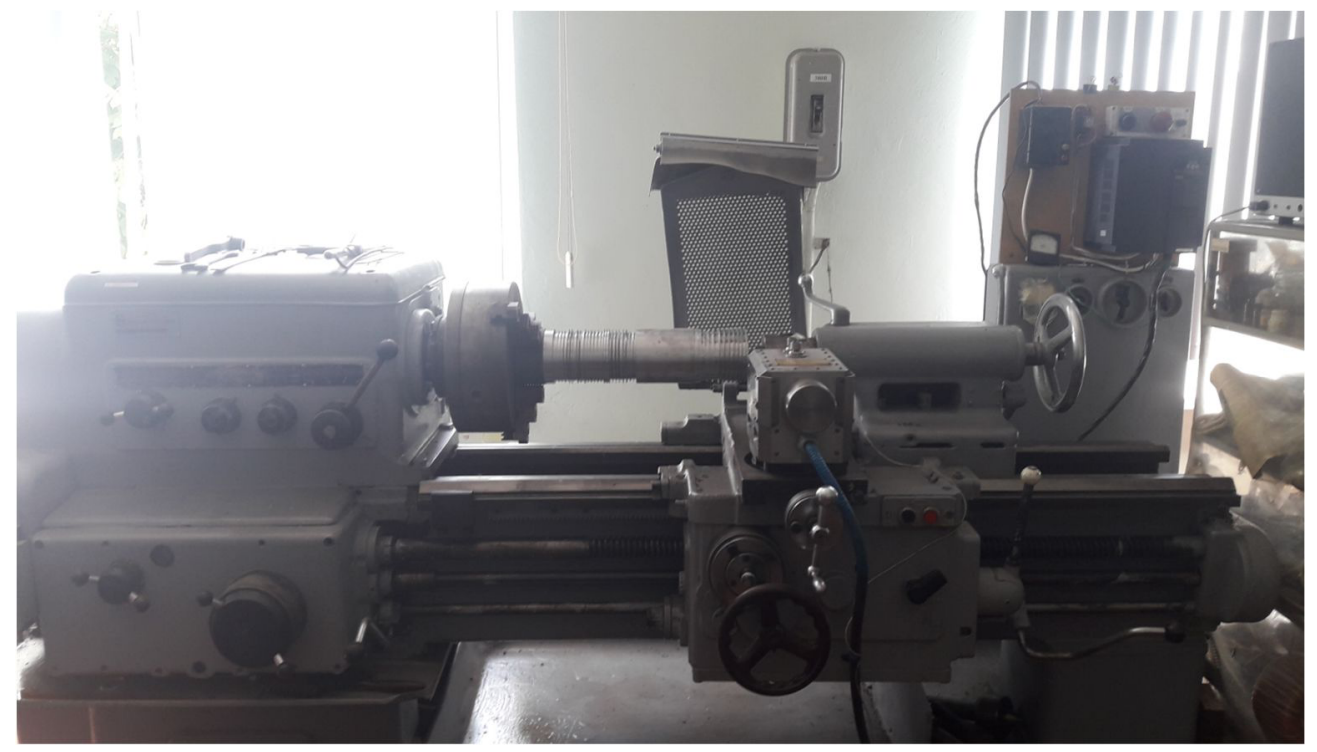

Fig. 1. Appearance of the experimental setup.

The machine presented in Figure 1 was previously upgraded, the engine controlling the operating modes on the machine is switched to frequency control, the frequency controller is shown in the upper right corner of figure 1. Thanks to this, it was possible to smoothly control the cutting speed inside the selected mode of the machine work. To measure the force response from the cutting process to the fore-forming movements of the tool, tool vibrations and the power of irreversible transformations (temperature), STD.201-1 is installed on the machine instead of the regular support. 


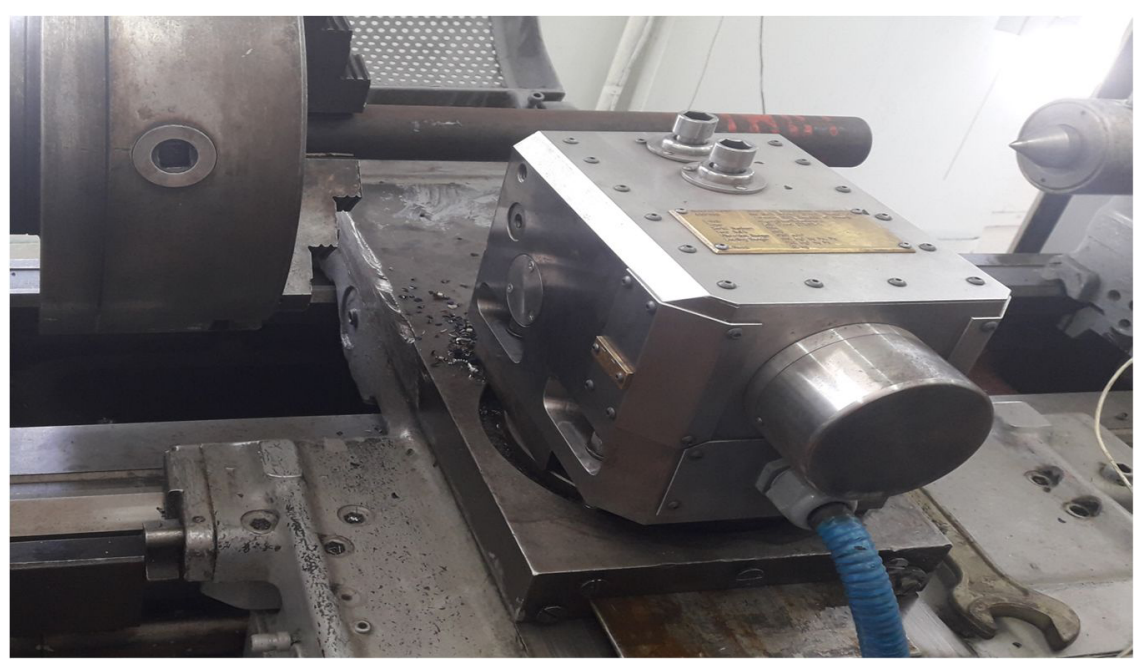

Fig. 2. Measuring unit.

The stand shown in Fig. 2, designed to study the dynamic and thermal processes occurring in the process of cutting of metals in various modes in the composition of lathes. STD.201-1 functionally consists of: a head-cutter, an interface unit, a personal computer and a set of cables. The head-cutter is installed on the caliper of the machine and includes a complex of sensors that convert the dynamic and vibrational effect on the cutting tool into electrical signals that come to the interface unit through a set of cables. The interface unit has a block structure and consists of electronic blocks from National Instruments. The electronic units are installed in the NI cDAQ-9174 chassis, which is connected to the PC via USB2.0.

At the stage of preparation for the planned experiment, the TNR $2020 \mathrm{~K} 11$ tool, widely used by Soviet manufacturers, was used with a replaceable five-edged plate 10113-110408 T15K6.To assess the wear of the instrument, an ordinary microscope was used, which allowed the area to be enlarged 24-fold, the fixing tool was attached to it at the time of evaluation. Photos from the worn part of the instrument were made through the lens of this microscope. The main purpose of the experiment was to determine the internal dynamic connection that occurs when turning on metal cutting machines. By this connection we mean the mutual influence of the tool wear on the cutting process and the cutting process on the tool wear. As we said earlier, this connection is carried out through the force reaction that forms in the cutting zone. Measurement of this reaction, as well as the quality of the processing, with simultaneous evaluation of the degree of the tool wear, allowed qualitatively determine the desired dynamic feedback. For such an experiment it is required continuously, with the same processing parameters, to make a certain part of the shaft type, while discretely controlling the degree of the tool wear and the temperature in the contact area of the tool with the workpiece. For more convenient presentation of information the program provides the ability to display the entire array of measurements in MS Excel. The results of the experiment were processed in the Matlab software package.

\section{Evaluation of tool wear and its relationship with temperature in the cutting zone}

Tool wear in the experiment was assessed on the back edge, for this, as already mentioned above, after each step of processing the instrument was photographed and photographed 
through the microscope objective. A photograph of the wear of the instrument along the posterior face at the last step of the experiment is shown in Fig. 3.

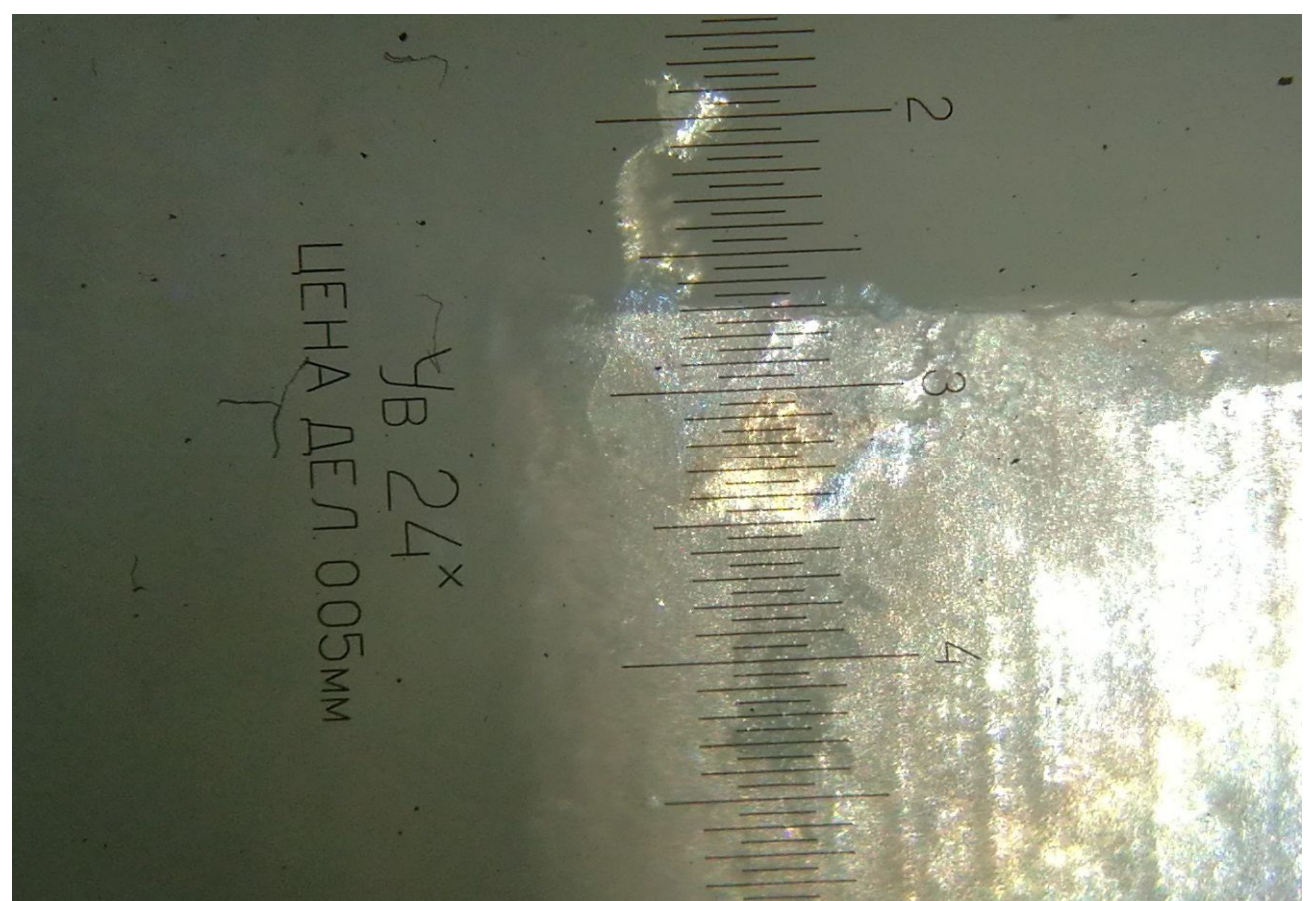

Fig. 3. Photo of a worn back surface of the tool at the seventh step.

After the seventh step of the experiment, the measured wear value over the back face exceeded the critical value and, according to our estimate, was $0.425 \mathrm{~mm}$. In connection with the attainment of the critical wear value, the experiment was discontinued, and the seventh step of the experiment became the last.The results of wear measurements in all seven steps of the experiment are represented by the following table of values.

Table 1. Results of the data processing.

\begin{tabular}{|c|c|}
\hline time, min & Wear, $\mathbf{~ m m}$ \\
\hline 0 & 0 \\
\hline 4 & 0,15 \\
\hline 7 & 0,2 \\
\hline 10 & 0,225 \\
\hline 12,5 & 0,25 \\
\hline 15 & 0,275 \\
\hline 17,2 & 0,325 \\
\hline 19 & 0,425 \\
\hline
\end{tabular}

As can be seen from the table, the total time of the experiment was 19 minutes, and the maximum wear value was $0.425 \mathrm{~mm}$. The same results in the form of a graph are shown in Fig.4 


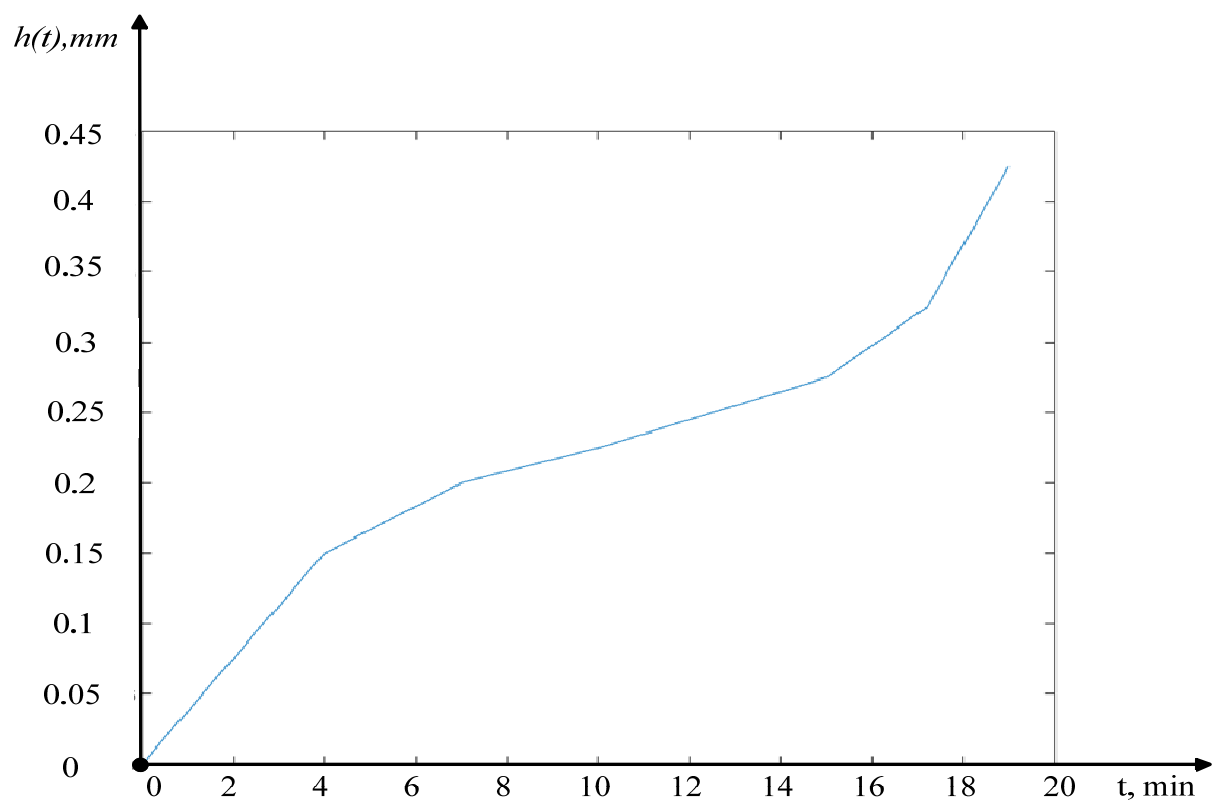

Fig. 4. Wear curve for the back face.

As seen from Fig. 5, the experimentally obtained wear curve completely corresponds to the wear curves obtained earlier in other experiments, which indicates a sufficiently high degree of adequacy of the experimental data obtained. The time variation of the temperature in the contact zone of the tool and the workpiece measured during the experiment, through the analysis of the natural thermocouple data, for the case of wear on the back edge equal to 0.15, is shown in Fig. 5.

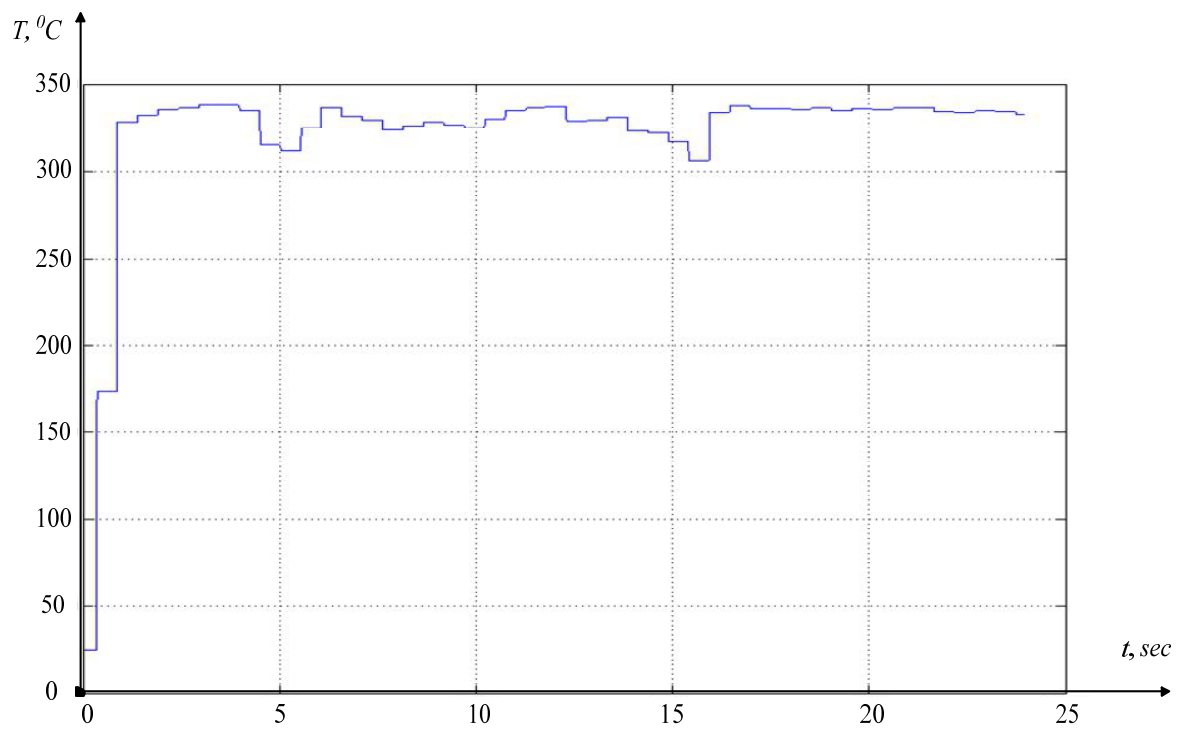

Fig. 5. Change in thermal energy at the first step of the experiment.

As can be seen from Fig. 6, the measured value of the temperature in the cutting zone when the tool is inserted into the workpiece increases from $25^{\circ} \mathrm{C}$ (ambient temperature) to 
about $330-340^{\circ} \mathrm{C}$. The processed results of the measured temperature in the contact zone of the tool and the workpiece for the case of tool wear close to critical are shown in Fig. 6.

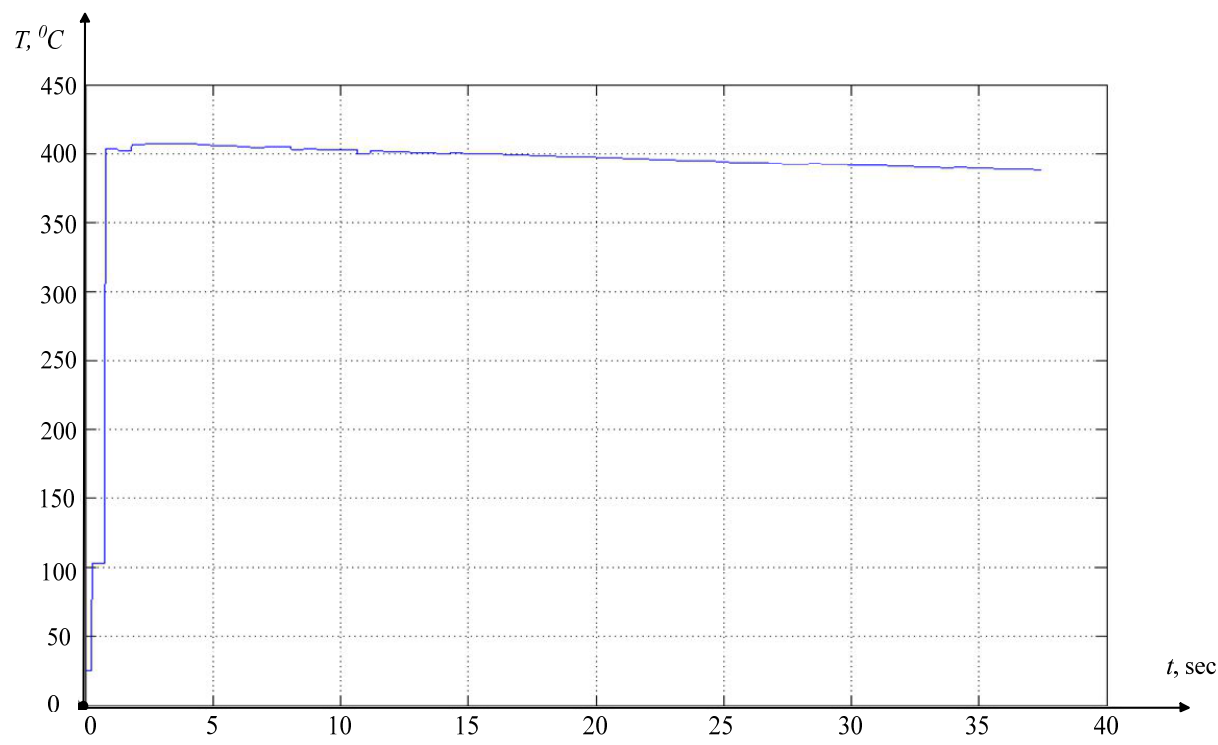

Fig. 6. The measured level of thermal energy at the last stage of the experiment.

As can be seen from Fig. 6, the increase in the level of thermal energy in the contact zone of the tool and the workpiece is maximal and reaches values close to $4100 \mathrm{C}$. Comparison of temperature growth.

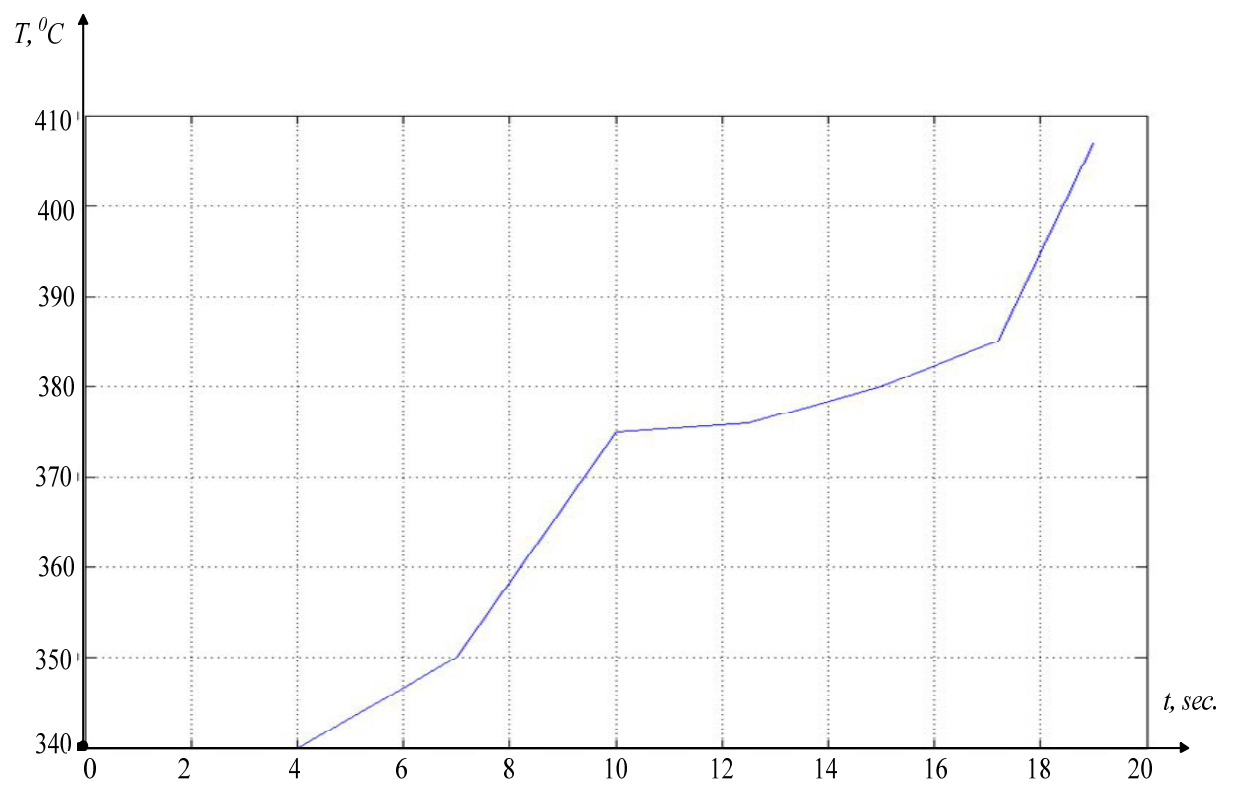

Fig. 7. Comparison of the heat level in the cutting zone and the degree of wear.

As can be seen from Fig. 7, at the initial stage, while the tool wear increases, the level of thermal energy in the contact zone of the tool and the workpiece increases substantially, 
subsequently at the stabilization site, the temperature level is stabilized, and at the exclusive stage at approaching the degree of deterioration to the critical value, the thermal energy in the contact zone begins to grow in the maximal manner.

\section{The discussion of the results}

The main conclusion on the work can be a conclusion about the repetition of the external form of the dependence of the level of thermal energy in the cutting zone on time, the graph of the depreciation of the instrument versus time. From this, one can speak of the possibility of linear interpolation of the heat level from the degree of wear during the synthesis of mathematical models of the processes that accompany the cutting of metals in metal-cutting machines. From the point of view of the possible explanation of this connection, it can be that with the increase in tool wear, the capacity of irreversible transformations in the processed article and in the tool itself grows, and the result of the growth of this capacity is the increase in the power of the heat released during processing.

\section{References}

1. T. N. Lonadze, Prochnost' i iznosostojkost' rezhushchego instrumenta (Mechanical Engineering, Moscow, 1982)

2. A.D. Makarov, Optimizaciya processov rezaniya (Mashinostroenie, Moscow, 1976)

3. V.A. Kudinov, Dinamika stankov (Dynamics of machine tools) (Mashinostroenie, Moscow, 1967)

4. I.G. Zharkov, Vibracii pri obrabotke lezvijnym instrumentom (Vibration when machining the edge tool) (Mashinostroenie, Moscow, 1986)

5. V. P. Lapshin, I. A. Turkin, Vestnik of DSTU, 5-6, 56 (2013)

6. V. P. Lapshin, I. A. Turkin, Russian Engineering Research, 35(10), 795 (2015)

7. V.L. Zakovorotny, V.P. Lapshin, T.S. Babenko, Procedia Eng, 206, 68 (2017)

8. A.R. Yildiz, Information Sciences 210, 81 (2012)

9. M. G. Faga, R. Mattioda, L. Settineri, CIRP Annals, 59 (1), 133 (2010)

10. J. Hu, Y. K. Chou, Wear, 263 (7), 1454 (2007) 